
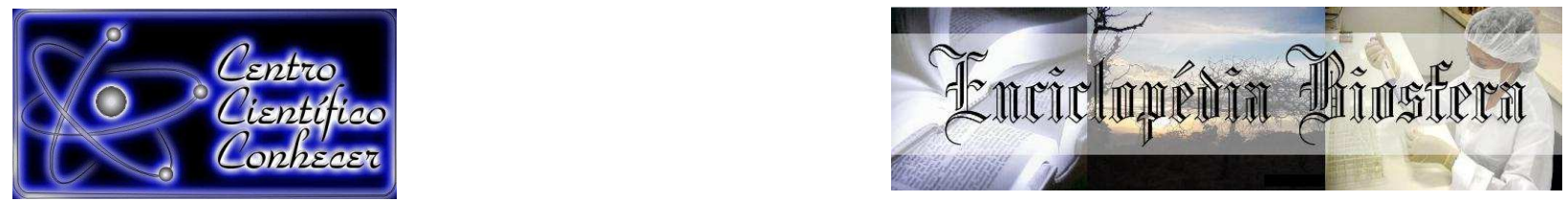

\title{
COMPORTAMENTO DE PREÇOS DE HORTALIÇAS FOLHOSAS NA REGIÃO METROPOLITANA DE BELÉM, ESTADO DO PARÁ
}

\footnotetext{
1Josiane Santos da Silva; ${ }^{2}$ Marcos Antônio Souza dos Santos; ${ }^{3}$ Carla Samara dos

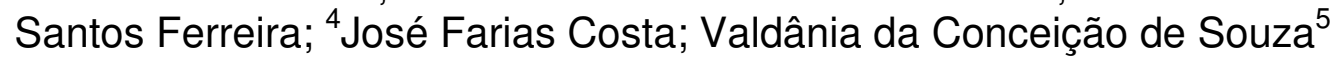

${ }^{1}$ Mestranda em Agroecologia e desenvolvimento Rural, Universidade Federal de São

Carlos, campus Araras-SP (e-mail: agricultura.j.s@gmail.com)

${ }^{2}$ Professor, Doutor do Instituto Socioambiental e dos Recursos Hídricos, Universidade Federal Rural da Amazônia

${ }^{3}$ Mestre em Agroecologia e desenvolvimento Rural, Universidade Federal de São Carlos, campus Araras-SP

${ }^{4}$ Técnico Agrônomo, Universidade Federal do Pará

${ }^{5}$ Mestranda em Agroecologia e desenvolvimento Rural, Universidade Federal de São Carlos, campus Araras-SP
}

\section{Recebido em: 02/10/2017 - Aprovado em: 21/11/2017 - Publicado em: 05/12/2017 DOI: 10.18677/EnciBio_2017B18}

\begin{abstract}
RESUMO
Estudos sazonais dos preços de hortaliças podem subsidiar o poder público na implantação de políticas de comercialização agrícola. Dessa forma, esse trabalho teve como objetivos: identificar a tendência dos preços de hortaliças e estimar os índices sazonais de preços de hortaliças na região metropolitana de Belém, PA. Os dados foram obtidos a partir do Sistema de Informação de Mercado Agrícola (SIMA), da Secretária de Agricultura do Estado do Pará (SAGRI) e disponibilizados pela Companhia Nacional de Abastecimento (CONAB). Os dados são referentes às médias mensais dos preços das hortaliças folhosas comercializadas no mercado atacadista, na Região Metropolitana de Belém, de janeiro 1999 a julho de 2017. Os preços das hortaliças comercializadas na Região Metropolitana de Belém sofrem forte influência das condições climáticas e os índices estacionais de preços mais elevados estão concentrados no primeiro semestre, configurando os picos de preços.
\end{abstract}

PALAVRAS-CHAVE: Agricultura Urbana; Horticultura; Mercado; Séries Temporais.

\section{BEHAVIOR OF LEAFY VEGETABLE PRICES IN THE METROPOLITAN REGION OF BELÉM, STATE OF PARÁ}

\begin{abstract}
Seasonal studies of the prices of vegetables can subsidize the public power in the implementation of agricultural marketing policies. Thus, the objective of this work is to identify the trend of vegetable prices and to estimate the seasonal indexes of vegetable prices in the metropolitan area of Belém, PA. The data were obtained from the Agricultural Market Information System (SIMA), from the Secretary of Agriculture of the State of Pará (SAGRI) and made available by the National Supply Company ENCICLOPÉDIA BIOSFERA, Centro Científico Conhecer - Goiânia, v.14 n.26; p.206 2017
\end{abstract}


(CONAB). The data refer to the monthly average prices of the hardwood vegetables marketed in the wholesale market, in the Metropolitan Region of Belém, from January 1999 to December 2013. The prices of vegetables sold in the Metropolitan Region of Belém are strongly influenced by climatic conditions and seasonal indices prices are concentrated in the first half of the year, setting the price spikes.

KEYWORDS: urban agriculture; horticulture; market; time series.

\section{INTRODUÇÃO}

O mercado de hortaliças é diversificado e com tendência de crescimento, abrangendo mais de uma centena de espécies, o que gera elevada renda por unidade de área cultivada. Para Melo e Vilela (2007), este mercado está vinculado à agricultura familiar, visto que cerca de $60 \%$ da produção brasileira é obtida de unidades produtivas com área inferior a 10 hectares (informação verbal ${ }^{1}$ ).

A intensa oscilação no preço, a sazonalidade e a elevada perecibilidade são características peculiares do mercado de hortaliças. Outra característica é a intensa utilização de mão de obra em todas as etapas do cultivo. Em cada hectare cultivado com hortaliças pode-se gerar de três a seis empregos diretos e indiretos, evidenciando a importância social no meio rural (VILELA; HENZ, 2000; GARRIDO; LUNARDON, 2008).

A despeito das variações cíclicas e sazonais das hortaliças, o setor hortícola mostra-se consideravelmente atraente. Alguns números podem comprovar isto, pois em condições naturais de mercado é estimada renda aproximada entre US\$2 mil e US\$ 20 mil por hectare (campo aberto). Complementarmente, ocorrem às técnicas de venda direta, realizadas pelos produtores direcionados especialmente aos sacolões, às feiras livres locais, mercados sobre veículos ou supermercados (SEBRAE, 2015).

Pelo exposto, é razoável analisar a variação sazonal dos preços hortícolas, e também sua importância. Vários estudos nessa linha de pesquisa vêm sendo desenvolvidos, como o trabalho realizado por Sousa (2016), Bento e Teles (2013) e Cardoso et al. (2013), mostrando que os conhecimentos a respeito do comportamento de preços de hortaliças, e mais especificamente das hortaliças folhosas, caso desta pesquisa, torna-se fundamental para análises, prognósticos e planejamento, além de gerenciamento do sistema de comercialização agrícola.

O estudo da sazonalidade dos preços é importante para ampliar a compreensão do mercado de hortaliças folhosas no estado do Pará, pois pode orientar os produtores para um planejamento de produção mais eficiente, o consumidor quanto a melhor época de compra, além de subsidiar o poder público na implantação de políticas de comercialização agrícola. Sendo assim esse trabalho teve como objetivos: avaliar o comportamento dos preços de hortaliças folhosas no mercado de Belém, Estado do Pará, no período de 1999 a 2017, bem como estimar os índices sazonais de preços desse produto na mesma localidade.

\section{MATERIAL E MÉTODOS}

\section{Fonte de Dados}

A pesquisa foi realizada na região metropolitana de Belém (RMB), incluindo os municípios de Ananindeua, Belém, Benevides, Castanhal, Marituba, Santa Bárbara do Pará e Santa Isabel do Pará. Os dados utilizados no trabalho foram 
coletados a partir do Sistema de Informação de Mercado Agrícola (SIMA), da Secretária de Agricultura do Estado do Pará (SAGRI) e disponibilizados através da Companhia Nacional de Abastecimento (CONAB). Os preços são referentes às médias mensais de hortaliças comercializadas na modalidade atacado, na RMB, no período de janeiro 1999 a julho 2017.

Foram escolhidas as hortaliças folhosas com maior volume de comercialização na RMB, conforme dados das Centrais de Abastecimento do Pará (CEASA). Neste estudo o foco foram as hortaliças folhosas (folha, flor e haste), abrangendo as seguintes espécies: Caruru (Amaranthus viridis L.), Cebolinha (Allium schoenoprasum L.), Couve (Brassica oleracea L. var. acephala), Coentro (Coriandrum sativum L.), Chicória (Cichorium endivia L.) e Jambú (Spilanthes oleracea).

\section{Análise de Sazonalidade}

Os preços utilizados na pesquisa são referentes às médias mensais de hortaliças comercializadas e foi utilizado o Índice Geral de Preços Disponibilidade Interna (IGP-DI) da Fundação Getúlio Vargas (FGV) com base referente a julho de 2017. Este deflator teve intuito de eliminar o efeito da inflação, sobre os preços nominais e assim proporcionar um diagnóstico comparativo dos preços ao longo do período analisado.

Para observar a sazonalidade das séries utilizou-se o método da Média Móvel Centralizada (MMC) em 12 meses, que também foi utilizado em trabalhos, como o de Mendes e Padilha Júnior (2007), Barroso Neto et al. (2015) e Sousa et al. (2016). Em seguida estimaram-se os Índices Estacionais Gerais (IEG), Índices Estacionais Médios (IEM) e os Índices Sazonais (ISAZ). Para isso, os preços reais foram divididos pelas respectivas médias móveis, obteve-se os IEG. A média dos IEG para cada mês do ano resultou no IEM. O Desvio Padrão e o Coeficiente de Variação (VC), também foram calculados. O limite inferior foi obtido, subtraindo-se o IEM do desvio padrão, já o limite superior foi resultado da somatória entre o IEM e o desvio padrão (MENDES; PADILHA JÚNIOR, 2007). Para análise dos dados e construção dos gráficos utilizou-se o software da Microsoft Excel ${ }^{\circledR}$, versão 2013.

\section{RESULTADOS E DISCUSSÃO}

De uma maneira geral a produção de hortaliças na $\mathrm{RMB}$ é realizada em âmbito familiar em pequenas áreas rurais próximas à capital. O mercado de hortaliças nessa região ainda é considerado incipiente, e segundo Homma (2011), são variados os tipos de hortaliças produzidas pelos agricultores na Amazônia, que utilizam principalmente os canteiros como área de cultivo, cujo total não ultrapassa um quarto de hectare, onde os produtores dão ênfase em cinco ou seis espécies, fazendo rodízio conforme o mercado.

Oliveira et al. (2017), discutem a pouca visibilidade do mercado de hortaliças na região e apontam alguns motivos para tal situação, entre eles: baixo rendimento, reduzido nível de tecnologia, além da necessidade de informações técnicas direcionadas à região. O seu comércio é realizado, de forma geral, em feiras livres e em entrepostos como a Central de Abastecimento do Pará (CEASA-PA).

De acordo com dados da CEASA-PA, em 2016, a quantidade de hortifrutigranjeiros comercializados no mercado atacadista, em Belém, por volume, foi de $245.956 .791 \mathrm{~kg}$ somando em valores $R \$ 625.254 .281,76$. Já na região Norte o subtotal comercializado chegou a $273.383 .493 \mathrm{~kg}$ o que gerou valor de $\mathrm{R} \$$ 
704.210.449,56. Baseado em dados históricos de preço das folhosas, através da CEASA-PA, e SIMA/SAGRI- PA, criou-se os gráficos de evolução de preços no período de janeiro de 1999 a julho de 2017 (Figura 1).
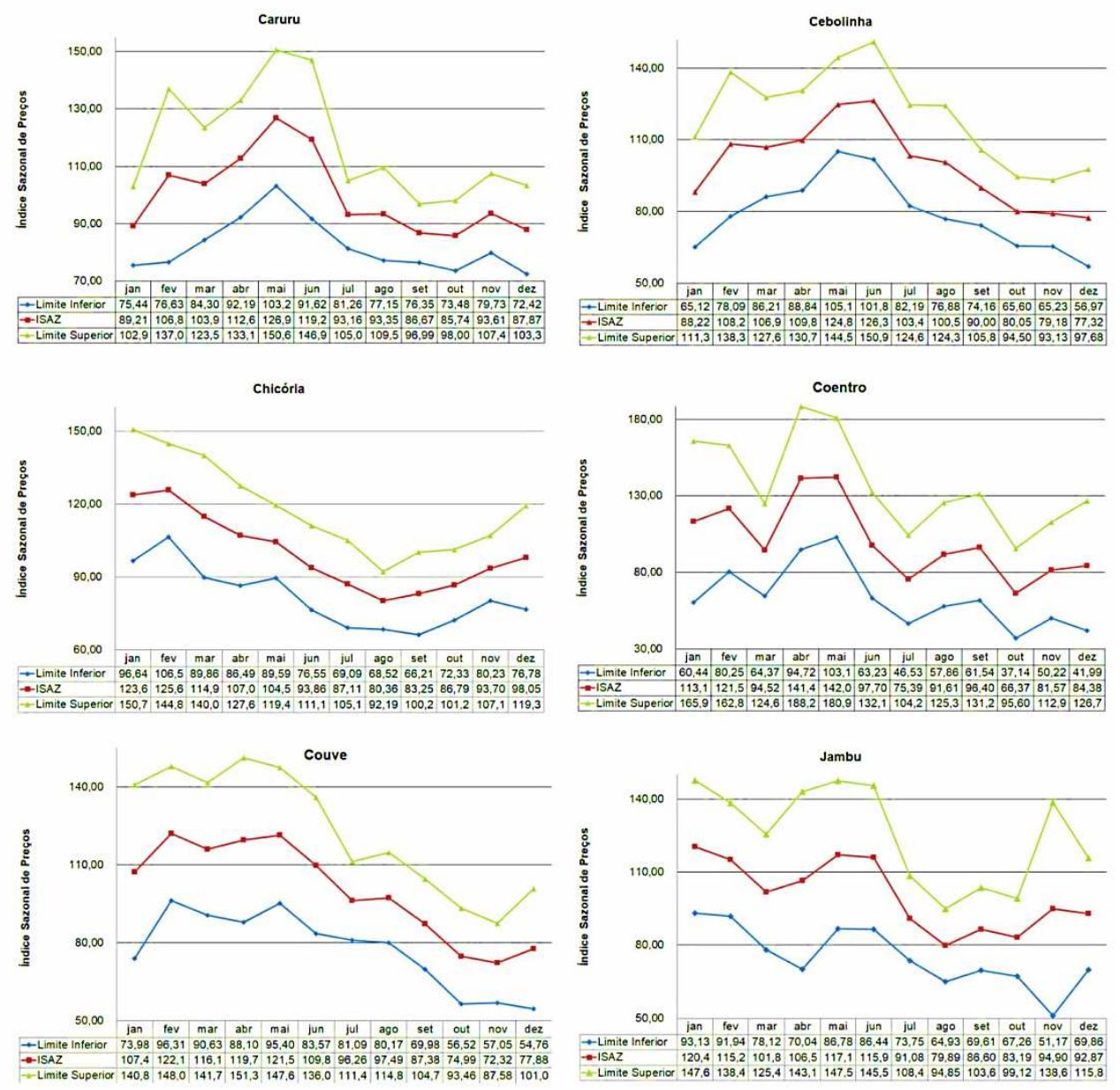

FIGURA 1. Limite superior, Limite inferior e Índice sazonal de preços da Cebolinha (Allium schoenoprasum L.), Caruru (Amaranthus viridis L.), Chicória (Cichorium endivia L.), Coentro (Coriandrum sativum L.), Couve (Brassica oleracea L. var. acephala) e Jambu (Spilanthes oleracea), respectivamente, de janeiro de 1999 a julho de 2017.

Fonte: Elaborado pelos autores

Conforme gráficos (Figura 1) observa-se que os limites superiores e inferiores tendem a acompanhar o comportamento dos índices sazonais dos preços analisados. Os gráficos mostram picos de altos preços no primeiro semestre, sinalizando entressafra e no segundo a tendência é de queda indicando safra.

O caruru apresenta preço em alta, do mês de fevereiro até junho, nestes meses apresenta pico de preço de $126,9 \%$ no mês de maio. Este comportamento pode ser explicado devido as condições ambientais da região que colaboram com doenças e tem como consequência direta ou indireta, falta ou escassez de produto 
no mercado, além de depender da decisão do produtor de plantar, pois é uma hortaliça essencialmente vinda de agricultura em pequenas áreas e complementar a renda do agricultor. No segundo semestre demonstra queda nos preços de julho a janeiro, e registra um Isaz mínimo de $85,74 \%$ em outubro o que caracteriza a safra do produto.

A cebolinha começa o ano em baixa de preços, e no mês seguinte, fevereiro, inicia aumento nos preços, estabilizando até o mês de abril, a partir deste mantêmse elevado até o mês de julho, nele ocorre pico de preço alto devido à entressafra, e os índices sazonais estão acima de 100.

A chicória apresentou maiores preços de janeiro a maio, neste momento pode-se considerar a entressafra, com pico no mês de fevereiro (125,6\%). Já do mês de junho até dezembro os índices sazonais ficaram abaixo de 100, indicando período da safra, com valor mínimo de $80,36 \%$ no mês de agosto. A chicória é uma hortaliça cultivada em quintais ou pequenos espaços e recebia poucos tratos culturais. As suas sementes normalmente são adquiridas na própria área de produção (GUSMÃO et al. 2003), o que está vulnerável as condições de área (doenças, grau de germinação das sementes, solo) e clima. Com a descoberta de suas características medicinais e organolépticas aumentou o interesse pelo estudo e produção, como no trabalho realizado por Gomes et al. (2013) refletindo no preço do produto.

O coentro que é a folhosa bastante consumida da região amazônica por ser utilizado na culinária, em peixes e mariscos, possui comportamento de alta e baixa pouco estável em relação aos preços. O mês de fevereiro mostra um índice sazonal de $121,5 \%$ enquanto no mês de março, 94,52\%. Este comportamento pode ser influenciado não só pela entressafra, mas também por ser cultura semeada diretamente no local de produção e associando-se a isso com a alta pluviosidade na região podem ocorrer perdas na colheita.

A couve apresentou comportamento de alta de preços a partir de janeiro até junho, com pico de alta de $122,1 \%$ no mês de fevereiro enquanto que no segundo semestre queda nos preços chegando ao mínimo de $72,32 \%$ no mês de novembro acompanhando as oscilações de safra e entressafra.

O Jambu, como as outras hortaliças, apresenta preços altos no primeiro semestre, com pico de $120,4 \%$ em janeiro e mínimo de $79,89 \%$ no mês de agosto, no segundo semestre, o que também foi demonstrado por Isshiki (2010). O jambu tem alta demanda na região Norte devido ao uso em pratos típicos, especialmente na época do Círio de Nazaré, quando o consumo aumenta, porém, os dados mostram que apesar da alta demanda o preço do produto não sobe muito, sobretudo a grande oferta o que provoca equilíbrio entre oferta e demanda.

Homma et al. (2011) discutem a importância de inovações tecnológicas para acompanhar a expansão das hortaliças para outros estados e partes do mundo, situação que vem se consolidando. Apesar do desenvolvimento, o jambu ainda é considerado uma planta de produção e consumo invisível, não constando nas estatísticas oficiais, apesar de ser bastante consumida na região e utilizada em cosméticos e uso medicinal. Ainda é considerado um produto sazonal, consumido principalmente em épocas de festas populares.

A partir da tabela 1, verifica-se as amplitudes dos preços reais praticados na $\mathrm{RMB}$. As maiores amplitudes de variação, que é a diferença entre o maior e o menor valor dos índices sazonais, foram observadas no coentro $(75,68 \%)$ e cebolinha $(49,06 \%)$ isso pode ser explicado em função da intensa dependência de cuidados e as doenças em época de alta pluviosidade. Pesquisa realizada por Capucho et al. 
(2015), mostrou que houve ocorrência de patógenos em mais de $50 \%$ dos canteiros avaliados, dentre as culturas, uma das mais atacadas encontra-se o coentro. Apesar de ser uma hortaliça relativamente rústica e possuir ciclo curto, é atacada por poucas doenças, as mais importantes são: o tombamento de mudas, os nematoides e a queima de folhas, podendo limitar a produção em épocas de estação chuvosa ou em plantio mal manejado (REIS 2016).

A cebolinha também é exigente em cuidados, e necessita de solos bem drenados, o que não ocorre em época de altas chuvas, na RMB. No Nordeste paraense chega a ocorrer os maiores índices de precipitação durante o ano, com valores superiores a $2.000 \mathrm{~mm}$ (LOPES, 2013).

TABELA 1. Amplitude dos preços médios reais das hortaliças na RMB.

\begin{tabular}{cc}
\hline Hortaliças & Amplitudes (\%) \\
\hline Cebolinha & 49,06 \\
Coentro & 75,68 \\
Caruru & 41,19 \\
Couve & 34,78 \\
Chicória & 45,31 \\
Jambu & 40,52 \\
\hline
\end{tabular}

Fonte: Dados da pesquisa

Como já comentado anteriormente, a pluviosidade na RMB tem forte influência na produção de hortaliças folhosas. Isto ocorre basicamente no primeiro semestre, isto favorece o desenvolvimento de patógenos, sobretudo, bactérias causando danos ao vegetal, o que provoca queda na produção influenciando diretamente no aumento de preço do produto. Soma-se aí, também, os grandes volumes de água no solo, ocupam espaço destinados a aeração, reduzindo a oxigenação, causando estresse e morte do vegetal, sendo que a umidade no solo deve estar próxima a capacidade de campo (cerca de 90\%) diferente do que ocorre no primeiro semestre na região, chegando a apresentar índices de saturação no solo.

No segundo semestre pode ser visualizado queda nos preços, ocasionado também pelo período de colheita (safra) da maioria das folhosas, sendo ofertada maior quantidade de produto no mercado ocasionando queda nos preços. Outro fator importante são as variedades adaptadas à região Amazônica, como as de polinização aberta e os híbridos, adaptados ao calor, tendendo a amenizar e até mesmo mudar o efeito da sazonalidade nas hortaliças

\section{CONCLUSÃO}

Os preços das hortaliças comercializadas na Região Metropolitana de Belém sofrem forte influência das condições climáticas e são determinados pelas forças de oferta e demanda. Os índices estacionais dos preços mais elevados estão concentrados no primeiro semestre. O estudo da sazonalidade dos preços é importante, pois pode direcionar os produtores para uma distribuição de produção mais eficiente, guiar o consumidor para a melhor época de compra, além de subsidiar o poder público na implantação de políticas de comercialização agrícola.

\section{REFERÊNCIAS}

BARROSO NETO, A. M. ARAÚJO, L. B. R. SOUSA, A. M. VASCONCELOS, M. R. A. BLEICHER, E. Fenologia de produção e comportamento de preços da Berinjela 
no estado do Ceará. Enciclopédia Biosfera, Centro Científico Conhecer - Goiânia, v.11 n.22; p. 1264, 2015.

BENTO, D. G. C.; TELES, F. L. A sazonalidade da produção agrícola e seus impactos na comercialização de insumos. Revista Científica do Centro de Ensino Superior Almeida Rodrigues. Rio Verde, FAR/ISEAR, Ano 1, № 1, 2013.

CARDOSO, M. V. SOARES, P. R. C. SILVA, J. C. G. L. JUNIOR, R. T. Estudo da sazonalidade do preço da celulose brasileira no mercado dos Estados Unidos em períodos cíclicos como apoio a estratégias empresariais. Scientia Forestalis, Piracicaba, v. 41, n. 97, p. 047-055, mar/ 2013.

CARVALHO, M. V. G. S. A.; PINHEIRO, A. M. G. S. A logística do abastecimento na RMB: o caso CEASA. Grande Belém: faces de desafios de uma metrópole insular. Disponível em: <http://redpgv.coppe.ufrj.br/index.php/es/produccion/articulos-cientificos/2010-1/440a-logistica-do-abastecimento-na-regiao-metropolitana-de-belem-o-caso-ceasa/file>. Acesso em: 02 abr. 2017.

CAPUCHO, A. S., BARROSO, K. A., GERVÁSIO, R. D. C. R., SILVA, S. D. P. D., \& ROCHA, A. M. D. S. (2015). Diagnóstico de doenças de plantas em hortas agroecológicas em Petrolina-PE. Extramuros-Revista de extensão da UNIVASF, 3(1).

GARRIDO, M.; LUNARDON, M. Análise da conjuntura agropecuária safra 2008/09, Secretaria da Agricultura e do Abastecimento, Departamento de economia rural. Paraná, 2008.

GOMES, R. F., DA SILVA, J. P., DE GUSMÃO, S. A. L., DE SOUZA, G. T. (2013). Produção de chicória da Amazônia cultivada sob densidades de cultivo e poda do pendão floral. Revista Caatinga, 26(3), 9-14. ISSN 1983-2125 (online).

GUSMÃO, S. A. L. GUSMÃO, M. T. A. SILVESTRE, W. V. D. Caracterização do cultivo de chicória do Pará nas áreas produtoras que abastecem a grande Belém. Horticultura Brasileira, Brasília, v. 21, n. 2, p.1-4, 2003.

HOMMA, A.K.O. SANCHES, R. S. MENEZES, A. J. E. A. et al. Etnocultivo do jambu para abastecimento da cidade de Belém, Estado do Pará. Amazônia: Ciência \& Desenvolvimento, Belém, v. 6, n. 12, jan./jun. 2011. Disponível em: < http://www.bancoamazonia.com.br/images/arquivos/institucional/biblioteca/revista_a mazonia/edicao12/n12_etnocultivo_do_jambu_p.pdf >. Acesso em: 25 mar 2017.

IBGE - Instituto Brasileiro de Geografia e Estatística. Senso Agropecuário, 2006. Disponível em: < http://www.sidra.ibge.gov.br/bda/pesquisas/ca/default.asp?o=2\&i=P> Acesso em: Acesso em 05 mar 2017.

ISSHIKI, $\mathrm{H}$. Análise estacional de preços do jambu no mercado atacadista de belém no período 2000-2009. 2010. Disponível em: < http://www.administradores.com.br/producao-academica/analise-estacional-de- 
precos-do-jambu-no-mercado-atacadista-de-belem-no-periodo-2000-2009/3643/>. Acesso em: 02 abr. 2017.

LOPES, M. N. G. (2013). Climatologia regional da precipitação no estado do Pará. Revista Brasileira de Climatologia, v. 12, n. 1, 2013. (Eletrônica).

MELO, P. C. T.; VILELA, N. J. Importância da cadeia produtiva brasileira de

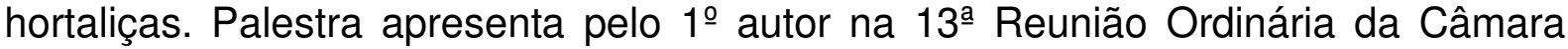
Setorial da Cadeia Produtiva de Hortaliças / MAPA, 2007, Brasília.

MENDES, J. T. G; PADILHA JR, J. B. Agronegócio: uma abordagem econômica. São Paulo: Pearson Prentice Hall, 2007.

REIS, A., \& LOPES, C. Doenças do coentro no Brasil. Embrapa Hortaliças-Circular Técnica (INFOTECA-E), 2016.

SEBRAE - Serviço Brasileiro de Apoio às Micro e Pequenas Empresas . 0 mercado de hortaliças no Brasil. 2015. Disponível em: < https://www.sebrae.com.br/sites/PortalSebrae/artigos/o-mercado-de-hortalicas-nobrasil,92e8634e2ca62410VgnVCM100000b272010aRCRD>. Acesso em: 02 abr. 2017.

SOUSA, A. M. TABOSA, F. J. S. NETO, A. M. B. FILHO, F. C. REIS, J. N. P. Análise do comportamento dos preços das principais frutas e hortaliças-fruto comercializados na Ceasa-Ce. Enciclopédia Biosfera, Centro Científico Conhecer Goiânia, v.13 n.23; p. 72, mai. $2016 . \quad$ DOI: 10.18677/Enciclopedia_Biosfera_2016_007.

VILELA, N. J.; HENZ, G. P. Situação atual da participação das hortaliças no agronegócio brasileiro e perspectivas futuras. Cadernos de Ciência \& Tecnologia. Brasília, v. 17, n. 1, p.71-89, jan./abr. 2000. < http://seer.sct.embrapa.br/index.php/cct/article/view/8863 >

OLIVEIRA, A. M. P. AGUIAR, R. M. BRONZE, A. B. S. JUNIOR, J. A.L. AVIZ, W. L. C. Desempenho de diferentes variedades de alface americana nas condições da Amazônia Oriental. Revista Ciência Agrícola, v. 14, n. 1, p. 1-5, 2017. ISSN 24473383. 